\title{
Coplanar Printed-Circuit Antenna With Band-Rejection Elements For Ultra-Wideband Filtenna Applications
}

\author{
Yingying Lu, Hung-Jui Lam and Jens Bornemann \\ University of Victoria, Victoria, BC, Canada
}

\section{Introduction}

Filtennas consist of wideband antenna structures, which incorporate narrowband filter elements for band selection or interference reduction [1]. Especially with respect to ultra-wideband (UWB) technology in the $3.1-10.6 \mathrm{GHz}$ range, it is essential that certain narrowband services be appropriately suppressed [2]. Recent activity focused on reducing the effect of IEEE 802.11a wireless local area network (WLAN) systems on UWB operation in the frequency range from 5.15 $\mathrm{GHz}$ to $5.85 \mathrm{GHz}$. Therefore, a number of so-called bandstop antennas (filtennas) in printed-circuit technology have been proposed, e.g. [3-7]. Since band-rejection elements are simple structures and easily integrated with printed-circuit technology, the entire filtenna concept offers low-cost fabrication and mass production. Moreover, the notched frequency range can be adjusted by changing the parameters of the band-rejection elements.

This paper presents three coplanar filtenna designs, which incorporate, first, a coplanar filter in the feed line, secondly, a u-shaped and, thirdly, an n-shaped slot in the center-conductor part of the coplanar UWB antenna.

\section{Designs and Results}

A recently introduced coplanar UWB antenna concept [8] is used as the base model for the filtenna applications. To verify the computational approach of the investigation, the antenna in [8] was simulated by three different EM-based software packages: CST Microwave Studio, Ansoft HFSS and MEFiSTo-3D. Very good agreement was achieved (not shown here for lack of space) and, therefore, the following results are based on CST computations only. The three different filtenna structures use FR4 substrates with $1.575 \mathrm{~mm}$ thickness and a substrate area of $\mathrm{W}=30 \mathrm{~mm}$ and $\mathrm{L}=40 \mathrm{~mm}$ (c.f. Fig. 1a). All simulations include a $50 \Omega$ coaxial connector, which also serves to connect the two ground planes of the coplanar feed line.

Fig. 1 demonstrates the first filtenna concept in which a coplanar filter similar to that presented in [9] is incorporated into the feed line. Basic design guidelines in [9] are followed for the filter design whose stand-alone performance is shown in Fig. 2a. The two $\left|\mathrm{S}_{11}\right|$ minima are due to the close proximity of the filter elements in Fig. 1b. The VSWR performance of the entire filtenna is shown in Fig. 2b and is compared with that of the original UWB antenna design (without the stopband 
filter). The notched frequency band is from $4.8 \mathrm{GHz}$ to $6.122 \mathrm{GHz}$, which covers the frequency range taken by WLAN. The maximum VSWR is 9 corresponding to $\left|\mathrm{S}_{11}\right|=-1.9 \mathrm{~dB}$. Note that the VSWR exceeds a value of 2 above $9.9 \mathrm{GHz}$. This is attributed to the wide center-conductor feed line, which is used to separate the two filter parts.

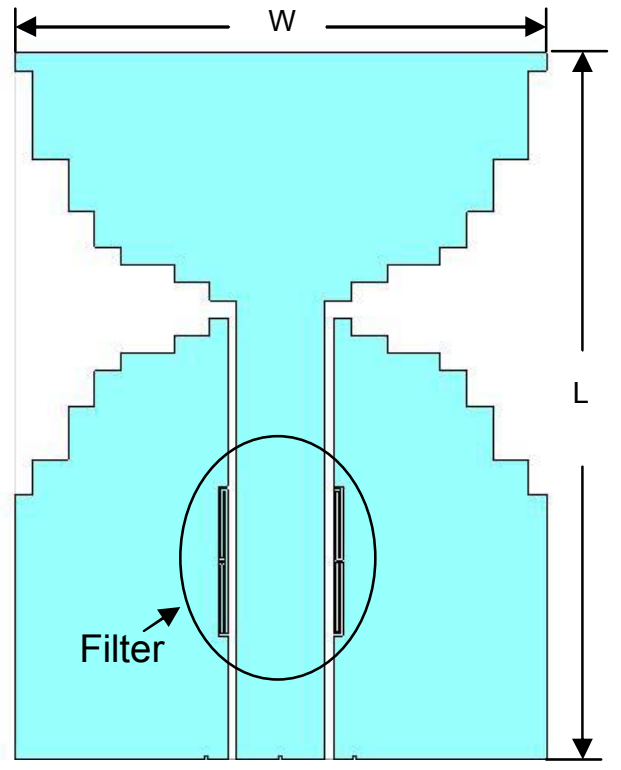

(a)
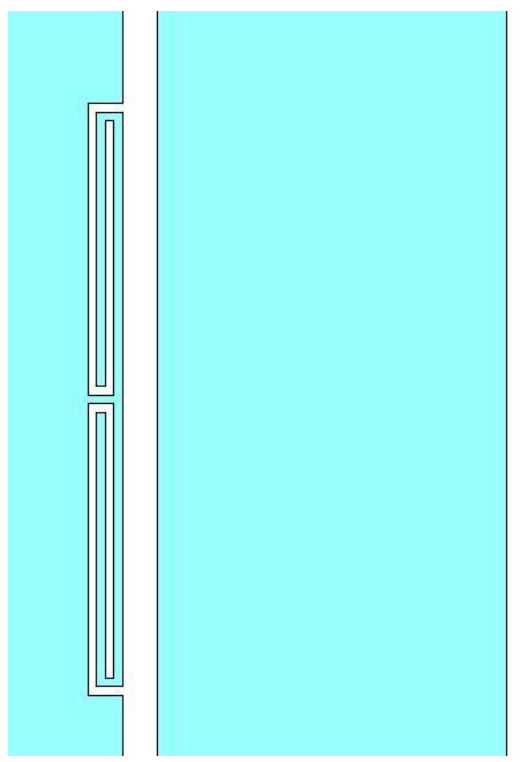

(b)

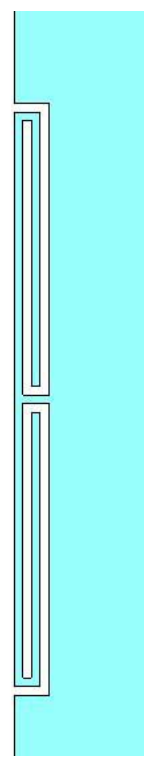

Fig. 1 Geometry of the first filtenna (a), and filter element (b).

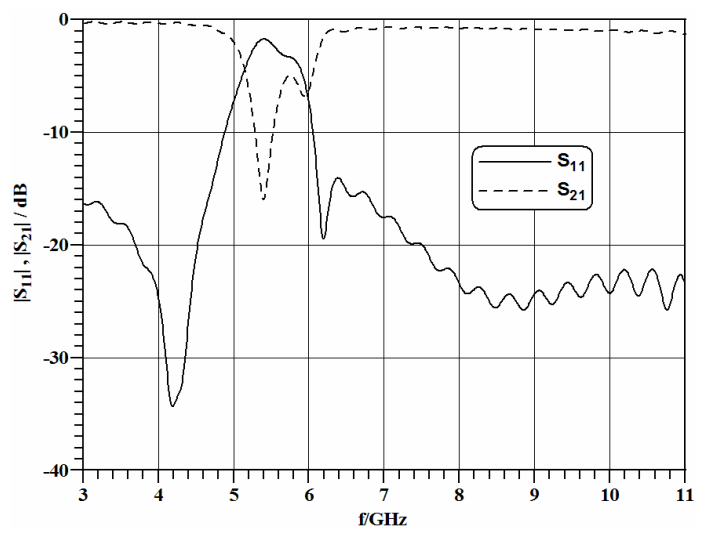

(a)

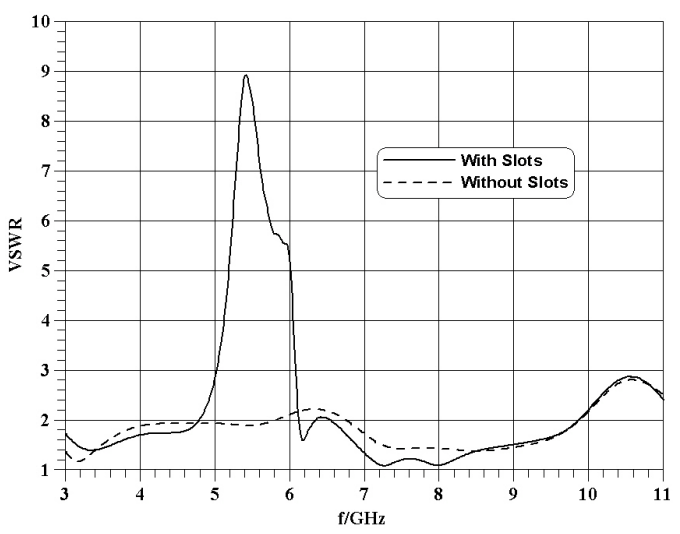

(b)

Fig. 2 Performance (a) of the bandstop filter in Fig. 1a ( $\mathrm{S}_{11}$ - solid line, $\mathrm{S}_{21}$ - dashed line), and VSWR of the first filtenna (b).

In our second filtenna design, the notched frequency range is adjusted by changing the length of a u-shaped slot [7] as shown in Fig. 3a. The total length of the slot is approximately $\lambda / 2$ at midband frequency and creates a notched range between $4.99 \mathrm{GHz}$ and $5.87 \mathrm{GHz}$, where the VSWR is significantly larger than 2 (c.f. Fig. 3 b). The maximum VSWR is 7.6 corresponding to $\left|\mathrm{S}_{11}\right|=-2.3 \mathrm{~dB}$. Note that due to the reduced width of the center feed line, the VSWR of the antenna without slot, as well as that of the slotted antenna in the respective frequency ranges, is now below 2 . 


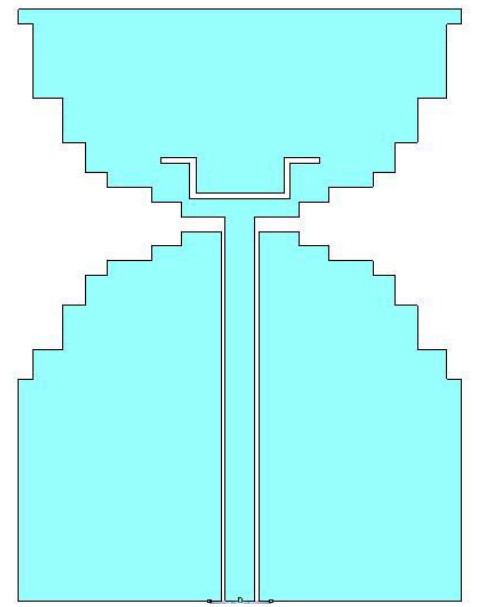

(a)

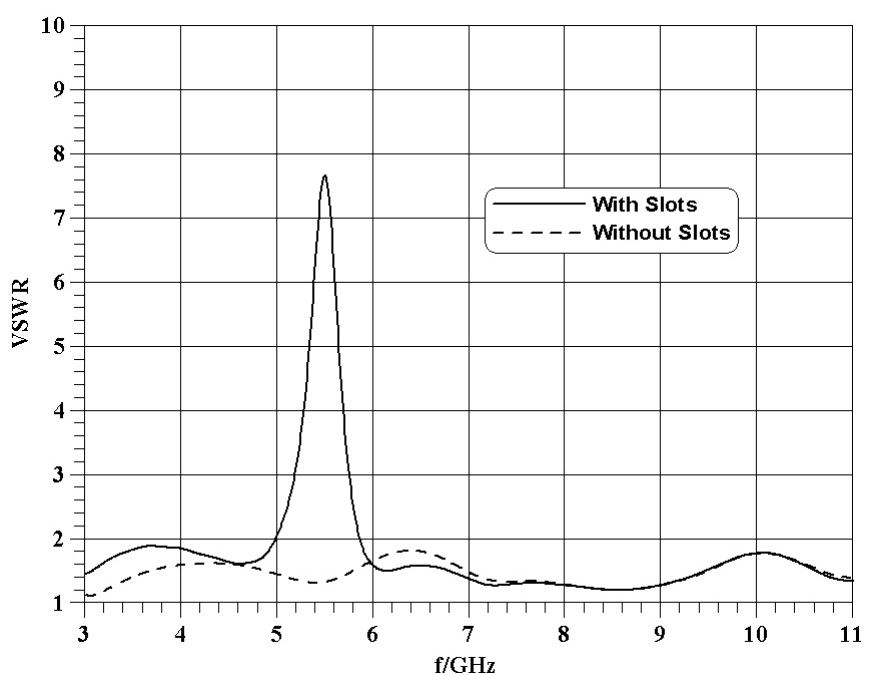

(b)

Fig. 3 Geometry (a) and VSWR of the filtenna with u-shaped slot (b).

Fig. 4 depicts the geometry and VSWR performance of a filtenna with an nshaped slot. The slot length is again adjusted to be approximately $\lambda / 2$ at midband notch frequency. The respective frequency range is from $5.15 \mathrm{GHz}$ to $5.95 \mathrm{GHz}$ and covers the WLAN frequency range. Compared to the UWB antenna without notch, the filtenna performs very well outside of the notched band. However, the peak VSWR is only 6.25 or $\left|\mathrm{S}_{11}\right|=-2.8 \mathrm{~dB}$. That means that approximately one half of the power carried by the WLAN service is still received with this antenna.

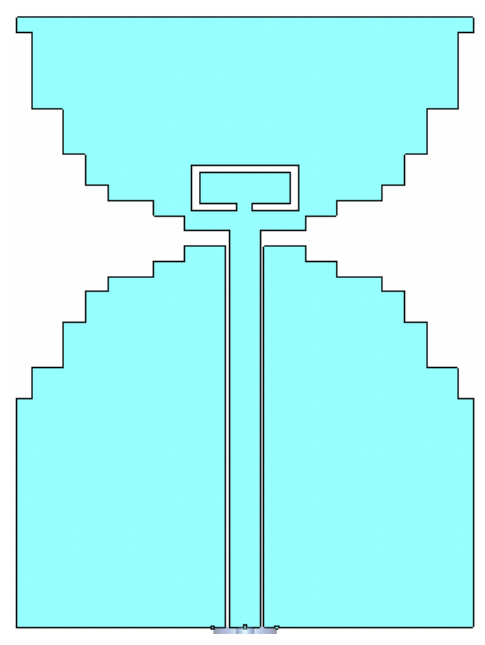

(a)

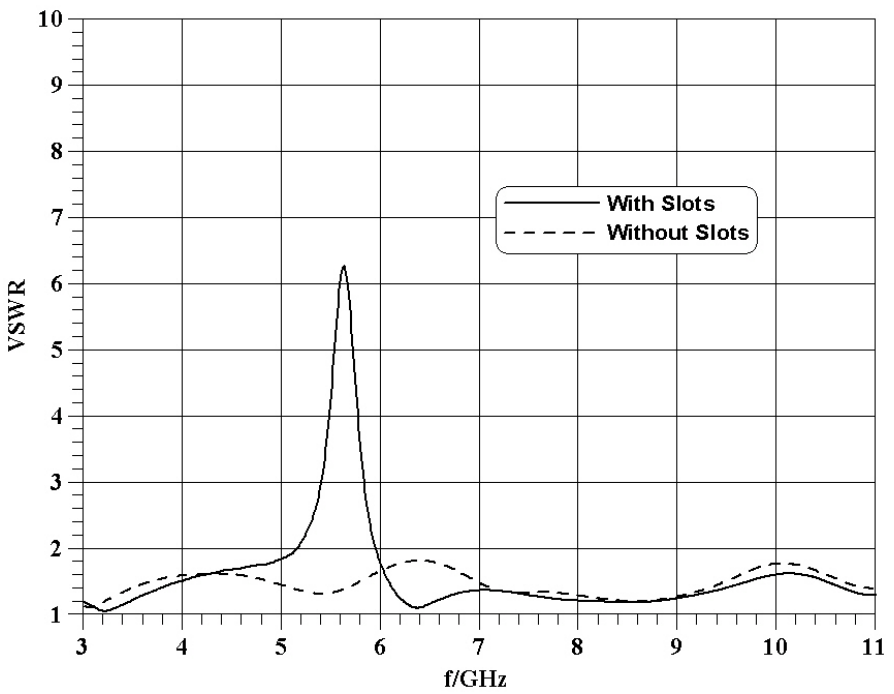

(b)

Fig. 4 Geometry (a) and VSWR of the filtenna with n-shaped slot (b).

\section{Conclusion}

In this paper, a coplanar printed-circuit UWB antenna with three different bandrejection elements for filtenna applications is proposed. The notched frequency 
bands of the proposed filtennas cover the WLAN frequency range for interference reduction between UWB and WLAN systems. The notched frequency bands of $u-$ shaped and $n$-shaped slots can be easily adjusted by changing the total length of the slot. However, better stopband performance is achieved by using a bandstop filter in the coplanar feed line of the UWB antenna.

Acknowledgement: The authors are grateful to Dr. Poman P.M. So of the University of Victoria for providing the CST Microwave Studio software platform. This work was supported by the TELUS Research Grant in Wireless Communications.

\section{References}

[1] G.Q. Luo, W. Hong, H.J. Tang, J.X. Chen, X.X. Yin, Z.Q. Kuai and K. Wu, "Filtenna consisting of horn antenna and substrate integrated waveguide cavity FSS," IEEE Trans. Antennas Propagat., Vol. 55, pp. 92-97, Jan. 2007.

[2] K. Rambabu, M.Y.W. Chia, K.M. Chan and J. Bornemann, "Design of multiple stopband filters for interference suppression in UWB applications," IEEE Trans. Microwave Theory Tech., Vol. 54, pp. 3333-3338, Aug. 2006.

[3] A.M. Abbosh, "Design of UWB planar antenna with subband rejection capability," Microwave Opt. Technol. Lett., Vol. 49, No. 11, pp. 2855-2859, Nov. 2007.

[4] S.J. Kim, H.S. Lee and Y.S. Kim, "A CPW-fed staircase monopole UWB antenna with band-notched frequency in the WLAN band," Microwave Opt. Technol. Lett., Vol. 49, No. 10, pp. 2545-2547, Oct. 2007.

[5] S. Lee, J. Baik and Y. Kim, "A coplanar waveguide fed monople ultrawideband antenna having band-notched frequency function by two foldedstriplines," Microwave Opt. Technol. Lett., Vol. 49, No. 11, pp. 2747-2750, Nov. 2007.

[6] Y. Ding, G. Wang and J. Liang, "Compact band-notched ultra-wideband printed antenna," Microwave Opt. Technol. Lett., Vol. 49, No. 11, pp. 26862689, Nov. 2007.

[7] W. Choi, J. Jung, K. Chung and J. Choi, "Compact microstrip-FED antenna with band-stop characteristic for ultra-wideband applications," Microwave Opt. Technol. Lett., Vol. 47, No. 1, pp. 89-92, Oct. 2005.

[8] H.-J. Lam and J. Bornemann, "Ultra-wideband printed-circuit antenna in coplanar technology," in 2007 IEEE EMC-S Int. Symp. Dig., TU-PM-1-7, pp. 1-4, Honolulu, USA, July 2007.

[9] A. Takacs, H. Aubert, P. Pons, T. Parra, R. Plana and J. Graffeuil, "Miniature coplanar bandstop filter for Ka-band applications based on original resonant coupling irises topology," IEE Electronics Lett., Vol. 40, No. 20, pp. 12741275, Sep. 2004. 